\title{
The Effect of Finger Puppets on Postoperative Pain in Children: A Randomized Controlled Trial
}

\author{
Aylin Kurt ${ }^{1}\left(\mathbb{C}\right.$, Muge Seval ${ }^{2}$ \\ ${ }^{1}$ Department of Pediatric Nursing, Bartin University, Bartin Turkey. \\ ${ }^{2}$ Department of Pediatric Nursing, Zonguldak Bulent Ecevit University, Zonguldak Turkey. \\ Correspondence Author: Aylin Kurt \\ E-mail: aylinkurt67@gmail.com \\ Received: 02.04.2020 Accepted: 09.03.2021
}

\begin{abstract}
Objectives: This study was conducted to determine the effect of finger puppet plays on the postoperative pain relief in children.

Methods: This study was conducted with 90 children who were aged between 1-5 years and who underwent surgery in 2016 in Turkey. The children were randomly divided into three groups. The control group $(n=30)$ was given routine treatment (analgesic treatment), intervention group $1(n=30)$ was played finger puppet by nurse, and intervention group $2(n=30)$ was played finger puppet by parents. Data collection instruments were "Child and Parent Assessment Form", "Children's Hospital of Eastern Ontario Pain Scale" and "PedsQL Health Care Parent Satisfaction Scale". After the intervention, the pain of children was evaluated by "Children's Hospital of Eastern Ontario Pain Scale" and the satisfaction of the parents was evaluated by "PedsQL Health Care Parent Satisfaction Scale".
\end{abstract}

Results: Mean score of the pain scale in the control group was found higher than the intervention groups 1 and $2(p<0.001)$. Mean score of satisfaction in control group was found lower than intervention group 1 and $2(p<0.001)$.

Conclusion: This study highlights that finger puppet plays can be used to decrease postoperative pain by the nurses as an independent role.

Keywords: Children, postoperative pain, pediatric nursing.

\section{INTRODUCTION}

Pain is one of the most important factors affecting life quality during postoperative period. Despite a large number of studies on postoperative pain management in children, no clear results have been obtained for pain relief (1-3). Children still experience moderate to severe postoperative pain (4). Thus, more studies are needed to find new and effective techniques for pain relief in children (5).

Distraction techniques constitute an independent part of a nurse's roles (6). Recent studies have shown that play is a perfect choice as a distraction technique for children. Play can be used as a distraction method helping children to cope with pain, anxiety and fear (7-10). Play can be highly important for nurses since they provide an opportunity to perform atraumatic care and family-centered care that constitutes the philosophy of pediatric nursing $(7,8,10)$.

Puppets are used as a part of playing activities for children in the hospital. They play an important role as a supportive factor for children having chronic diseases and for children in case of acute conditions. Puppets were found to be effective in decreasing aggression in children with attention deficit disorder and hyperactivity (11), in effective management of the disease in children with type 1 diabetes (12), in coping with disease and expression of feelings and thoughts for the disease in children diagnosed with cancer (13).

In recent years, research on distraction and preparation for children has been advanced (7-10). However, in the literature, no study was found reporting its use during postoperative period among children. Therefore, this study was carried out to determine the effect of distraction techniques (finger puppet plays) on the elimination of postoperative pain among children. It is important nursing research on pediatric surgical care, especially pain management, since it is difficult to evaluate pain in children.

\section{MATERIAL AND METHODS}

\subsection{Study Design and Sample}

This randomized controlled study was carried out in Pediatric Surgery Service of Zonguldak Obstetrics and Pediatrics 
Hospital in Turkey. The number of children within each group was determined as 26 at least based on the calculations made in G-Power 3.1 Demo package program for an effect size of 0.8 and a power of $80 \%$. However, it was decided to include 30 cases in each group due to the probability of any withdrawals from the study by any parents and children. Inclusion criteria of the study were the following: 1 - The child should be operated, 2 - The child should be aged between 1-5 years old, 3 - The child should not have a disability impairing facial expression, 4 - The child and the parent should be voluntary to participate in the study. Children were assigned to groups randomly based on their order of hospitalization. This study was conducted with 90 children who were aged between 1-5 years old who underwent elective surgery. The patients were randomly divided into a control group and two intervention groups as shown in consort flow diagram (Figure 1).

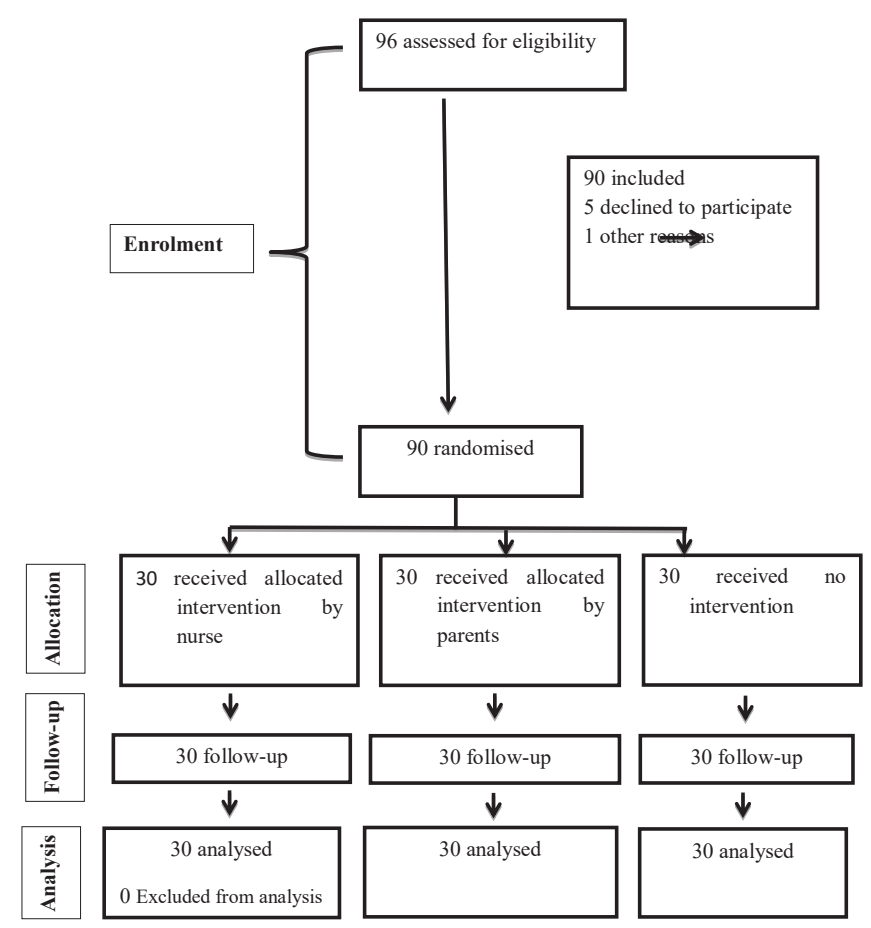

Figure 1. Flow diagram of the progress through the phases of the study

\subsection{Data Collection Instruments}

Child and Parent Assessment Form: This form included some questions about the socio-demographic characteristics of the child and the family, the name of the child's surgery, the presence of other illnesses, the number of children and the type of admission to the hospital.

Children's Hospital of Eastern Ontario Pain Scale in Young Children (CHEOPS): This scale was developed by Patrich J. McGrath et al. in order to evaluate postoperative pain among children; and consisted of 6 items including cry, facial expression, verbal responses, torso, wound evaluation and legs. Item 1 (cry) is evaluated with a minimum score of 1 and a maximum score of 3 points; items 2 (facial expression) and
3 (verbal responses) are evaluated with a minimum score of 0 and a maximum score of 2 points and items 4 (torso), 5 (wound evaluation) and 6 (legs) are evaluated with a minimum score of 1 and a maximum score of 2 points. The lowest total score of the scale is 4 whereas the highest score of the scale is 13. A high total score obtained from the scale shows that the child has a higher pain during postoperative period (14). The validity and reliability study of this scale in Turkish was conducted by these researchers (15) and the Cronbach's alpha internal consistency coefficient was found as $\alpha=0.87$ in this study.

PedsQL Health Care Parent Satisfaction Scale (Version 3.0): This is a questionnaire including 25 questions which was developed by James W Varni in 1999. The questions included in this inventory are for measuring satisfaction from healthcare services provided. The scale is composed of six subscales including information, inclusion of family, communication, technical skills, emotional needs and overall satisfaction. Its adaptation to Turkish was conducted by Ulus and Kubilay (16). Internal consistency analysis of the inventory was performed in the context of reliability studies of the scale; and Cronbach's alpha internal consistency coefficient was found as $\alpha=0.93$ (16).

\subsection{Procedure}

The sample of the study was composed of children who underwent surgery between May and August 2016 and who were aged between 1-5 years and had no any chronic diseases. The children included in the study were randomly assigned to three groups by the researchers according to the order of hospitalization. Among the groups, first one (control group) was given routine treatment (analgesic treatment), the second one (intervention 1 - no analgesic treatment) was played finger puppet plays by a nurse (that nurse was one of the researchers and working in that pediatric unit where this study was conducted), and the third group (intervention 2 - no analgesic treatment) was played finger puppet plays by the parents. The children underwent surgery with general anesthesia and the children for intervention groups didn't use analgesic treatment by the decision of the operating surgeon. The children for control group received acetaminophen (1015 milligrams per kilogram) for an analgesic treatment. The interventions and evaluations by the scales were conducted an hour later the surgery when the children were totally awake and needed an analgesic treatment.

Puppets are used as a part of playing activities for children in the hospital. They play an important role as a supportive factor for children having chronic diseases and for children in case of acute conditions. Despite playing the puppet, the nurse or person is invisible in the environment due to the child's focus on the puppet. Therefore, the child does not have a fear of nurses. The nurse transmits her own knowledge to the child, hidden (17). The puppets used in the study are made of felt by the researcher-nurse (Figure 2). Since these puppets made of felt are washable and easy to 
reconstruct if desired, the risk of carrying infections is tried to be minimized.

The texts used for puppet plays were written by a child development expert in accordance with the development of children aged between 1-5 years. At the same time, the researcher-nurse (AK) had training on puppet plays from a child development expert. The parents were trained by the researcher nurse on how to play puppet plays one day before the surgery (first day of hospitalization). The training was planned for 15-20 minutes but that time was extended with the questions of the parents. After the intervention, the pain of children was evaluated by "Children's Hospital of Eastern Ontario Pain Scale" and the satisfaction of the parents was evaluated by "PedsQL Health Care Parent Satisfaction Scale".

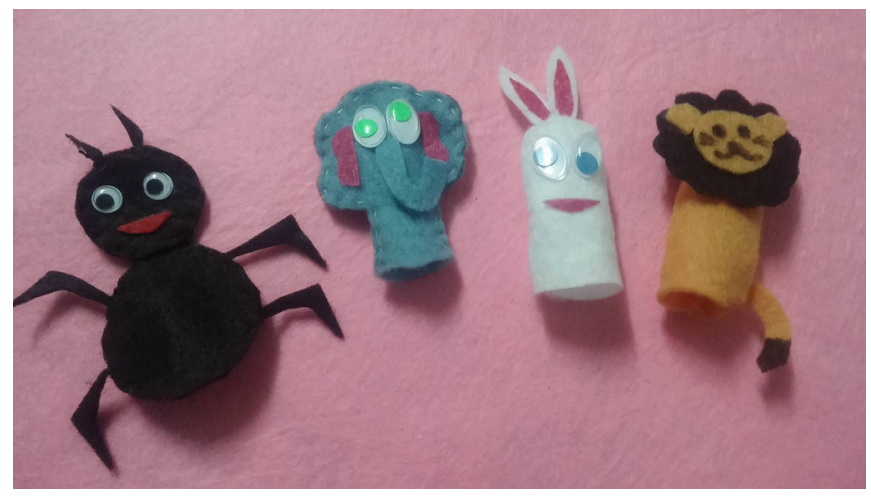

Figure 2. Examples of Finger Puppets that were used for Puppet Plays

\subsection{Data Analysis}

G-power 3.1 Demo package program was used to determine sample size. "SPSS for Windows 16.00 " statistical program was used to analyze data. Intraclass correlation analysis was performed to assess pre-treatment of the study. Percentage distribution and Pearson chi-square test were used in the analysis of socio-demographic characteristics of the children and their parents. The differences between groups based on the variables were tested by one way analysis of variance (ANOVA) and complementary posthoc analysis was used to determine the sources of the differences between groups.

\subsection{Ethical Consideration}

Ethics committee approval for the study was obtained from Kocaeli University Non-Interventional Clinical Research Ethics Committee (Date: 25/05/2016 and approval No. 2016/12). The written permission was obtained from the administration of the Zonguldak Bülent Ecevit University Institution of Health Sciences (Date: 27/06/2016 and approval No. 2016/18). Data collection was performed based on the voluntary participation of the individuals enrolled in the study. Parents were informed about the aim of the study and the confidentiality of all data, and their written consents were received. The research conforms to the provisions of the Declaration of Helsinki in 1995 (as revised in Brazil 2013).

\section{RESULTS}

This research was carried out on 90 patients aged 1-5 years who underwent elective surgery. The patients were randomly divided into a control group and two intervention groups. In the control group, 27 of the children (90.0\%) were male, 9 (30.0\%) were 3 years old and 27 (90.0\%) had circumcised. Twelve (40.0\%) of the children's mothers and $15(50.0 \%)$ of the fathers graduated from high school. In the intervention 1 group, 27 (90.0\%) of the children were male, 9 (30.0\%) were 3 years old and 26 (86.7\%) were circumcised. Thirteen (43.3\%) of the children's mothers and $15(50.0 \%)$ of the fathers graduated from high school. In the intervention 2 group, 28 (93.3\%) of the children were male and 5 (16.7\%) were 3 years old and 28 (93.3\%) were circumcised. Sixteen (53.3\%) of the children's mothers and $13(43.3 \%)$ of the fathers graduated from high school (Table 1). There were no statistically significant differences between the three groups according to the descriptives as shown in Table 1 ( $p>0.05)$. Children's pain and parental satisfaction do not make a difference according to sociodemographic data.

\subsection{Comparison of Pain Levels of Children between the Groups}

Analysis of variance (ANOVA) results considering pain scores of children in control, intervention 1 and intervention 2 groups were given in Table 2.

CHEOPS scores of the children in control group $(9.470 \pm 1.925)$ were found to be higher than the children in intervention group 1 (7.130 \pm 1.871$) \quad(p<0.001)$. CHEOPS scores of the children in the control group $(9.470 \pm 1.925)$ were found to be higher than CHEOPS scores of the children in intervention group $2(6.470 \pm 1.978)(p<0.001)$ (Table 2$)$.

\subsection{Comparison of Anxiety Levels of Parents between the Groups}

In Table 3, analysis of variance (ANOVA) results considering PedsQL scale scores of parents in control, intervention group 1 and intervention group 2 were given.

PedsQL scores of the parents in intervention group 1 $(3.283 \pm 0.401)$ were found to be higher than the parents in control group $(2.121 \pm 0.360)(p<0.001)$. PedsQL scores of the parents in intervention group $2(3.288 \pm 0.433)$ were found to be higher than the parents in control group $(2.121 \pm 0.360)$ $(p<0.001)$ (Table 3). 
Table 1. Descriptives and chi-square analysis of sociodemographic factors among the children in control, intervention 1 and 2 groups

\begin{tabular}{|c|c|c|c|c|c|c|c|c|}
\hline & & \multicolumn{2}{|c|}{ Control } & \multicolumn{2}{|c|}{ Intervention1 } & \multicolumn{2}{|c|}{ Intervention2 } & \multirow{2}{*}{$\mathbf{p}$} \\
\hline & & $n$ & $\%$ & $\mathrm{n}$ & $\%$ & $n$ & $\%$ & \\
\hline \multirow{2}{*}{ Sex } & Female & 3 & 10.0 & 3 & 10.0 & 2 & 6.7 & \multirow{2}{*}{$\begin{array}{l}X^{2}=0.274 \\
p=0.872\end{array}$} \\
\hline & Male & 27 & 90.0 & 27 & 90.0 & 28 & 93.3 & \\
\hline \multirow{5}{*}{ Age (years) } & 1 & 6 & 20.0 & 5 & 16.7 & 7 & 23.3 & \multirow{5}{*}{$\begin{array}{l}X^{2}=2.798 \\
p=0.946\end{array}$} \\
\hline & 2 & 6 & 2.0 & 5 & 16.7 & 5 & 16.7 & \\
\hline & 3 & 9 & 30.0 & 9 & 30.0 & 5 & 16.7 & \\
\hline & 4 & 5 & 16.7 & 5 & 16.7 & 6 & 20.0 & \\
\hline & 5 & 4 & 13.3 & 6 & 20.0 & 7 & 23.3 & \\
\hline \multirow{4}{*}{ Type of surgery } & Lingual phrenectomy & 1 & 3.3 & 1 & 3.3 & 1 & 3.3 & \multirow{4}{*}{$\begin{array}{l}X^{2}=4.874 \\
p=0.560\end{array}$} \\
\hline & Inguinal hernia & 2 & 6.7 & 3 & 10.0 & 0 & 0.0 & \\
\hline & \begin{tabular}{|l} 
Circumcision \\
\end{tabular} & 27 & 90.0 & 26 & 86.7 & 28 & 93.3 & \\
\hline & Umbilical hernia & 0 & 0.0 & 0 & 0.0 & 1 & 3.3 & \\
\hline \multirow{4}{*}{$\begin{array}{l}\text { Education level } \\
\text { of mother }\end{array}$} & Literate & 1 & 3.3 & 3 & 10.0 & 2 & 6.7 & \multirow{4}{*}{$\begin{array}{l}X^{2}=4.365 \\
p=0.627\end{array}$} \\
\hline & \begin{tabular}{|l} 
Primary school \\
\end{tabular} & 12 & 40.0 & 10 & 33.3 & 15 & 50.0 & \\
\hline & High school & 12 & 40.0 & 13 & 43.3 & 7 & 23.3 & \\
\hline & University & 5 & 16.7 & 4 & 13.3 & 6 & 20.0 & \\
\hline \multirow{4}{*}{$\begin{array}{l}\text { Education level } \\
\text { of father }\end{array}$} & Literate & 0 & 0.0 & 1 & 3.3 & 0 & 0.0 & \multirow{4}{*}{$\begin{array}{l}X^{2}=2.926 \\
p=0.818\end{array}$} \\
\hline & Primary school & 10 & 33.3 & 8 & 26.7 & 11 & 36.7 & \\
\hline & \begin{tabular}{|l|} 
High school \\
\end{tabular} & 15 & 50.0 & 16 & 53.3 & 13 & 43.3 & \\
\hline & University & 5 & 16.7 & 5 & 16.7 & 6 & 20.0 & \\
\hline
\end{tabular}

$X^{2}$ : Chi-square test

Table 2. Analysis of variance (ANOVA) results considering pain scores of children in control, intervention 1 and intervention 2 groups

\begin{tabular}{|c|c|c|c|c|c|c|c|c|c|}
\hline & \multicolumn{2}{|c|}{$\begin{array}{c}\text { Control } \\
\text { (1) }\end{array}$} & \multicolumn{2}{|c|}{ Intervention 1 (2) } & \multicolumn{2}{|c|}{ Intervention 2 (3) } & \multirow[t]{2}{*}{$\mathbf{F}$} & \multirow[t]{2}{*}{$\mathbf{p}$} & \multirow[t]{2}{*}{ Comparison } \\
\hline & $\mathbf{M}$ & SD & M & SD & M & SD & & & \\
\hline Pain Scores of Children (CHEOPS) & 9.470 & 1.925 & 7.130 & 1.871 & 6.470 & 1.978 & 20.089 & $0.000 *$ & $\begin{array}{l}1>2 \\
1>3\end{array}$ \\
\hline
\end{tabular}

CHEOPS: Children's Hospital of Eastern Ontario Pain Scale, ${ }^{*} p<0.001$

Table 3. Analysis of variance (ANOVA) results considering PedsQL scale scores of parents in control, intervention group 1 and intervention group 2

\begin{tabular}{|c|c|c|c|c|c|c|c|c|c|}
\hline & \multicolumn{2}{|c|}{$\begin{array}{l}\text { Control } \\
\text { (1) }\end{array}$} & \multicolumn{2}{|c|}{ Intervention 1 (2) } & \multicolumn{2}{|c|}{ Intervention 2 (3) } & \multirow[t]{2}{*}{$\mathbf{F}$} & \multirow[t]{2}{*}{$\mathbf{p}$} & \multirow[t]{2}{*}{ Comparison } \\
\hline & M & SD & M & SD & $M$ & SD & & & \\
\hline $\begin{array}{c}\text { PedsQL Scale Scores of } \\
\text { Parents } \\
\end{array}$ & 2.121 & 0.360 & 3.283 & 0.401 & 3.288 & 0.433 & 85.092 & $0.000^{*}$ & $\begin{array}{l}2>1 \\
3>1\end{array}$ \\
\hline
\end{tabular}

${ }^{*} p<0.001$

\section{DISCUSSION}

There has been an ongoing research for evaluating the effect of play, which are one of the distraction techniques that are often used in the hospitals, on the children during postoperative period $(7,9,18)$. Nurses play a key role in the management of postoperative pain of children in the hospital $(2,19-21)$. Yun et al. (9) reported that children experienced less anxiety and less pain during postoperative period after having a training on pre - and postoperative periods from clown nurses. Moreover, Fincher et al.(7) reported that training given through play by game-trained experts was effective in eliminating postoperative pain in children. He et al.(18) found that children and parents, who had a onehour therapeutic game intervention, experienced anxiety more than the ones who did not. In the same study, it was also reported that children having less anxiety experienced less postoperative pain. At the end of this study, children in control group were found to experience more pain compared to the children in the first intervention group (the group 
which was played finger puppet game by the nurse). Thus, results are similar to the relevant data in the literature.

Parents may be one of the most important factors affecting pain of children during postoperative period (8,22-24). Parents have significant roles in the management of pain at home during postoperative period, and they may feel themselves desperate since they may become incapable of adjusting analgesic drug doses (22,24-26). Chorney et al.(27) emphasized that parents wanted to be trained especially on distraction techniques in postoperative pain management of their children. Therefore, family should be included in postoperative pain management of children $(22,28)$. Ullan et al.(8) divided 95 children aged between 1-7 years old into two groups during postoperative period; and one group was played a game using a toy by the parents and the other group did not undergo any intervention. In conclusion, it was reported that children in the group which played game with parents experienced less pain compared to the children who did not play.

When the effect of the inclusion of parents during postoperative period on the children was examined in the literature, positive effects have been observed. At the end of this study, it was found that children in control group experienced more pain compared to the children in the second intervention group where parents played finger puppet plays.

Besides the studies reporting that parents have a positive effect on the children during postoperative period, there are also studies indicating some negative effects (29). Scalford et al.(29) stated that children, who were kept together with their parents during early postoperative period, experienced more pain. The reason of this was considered to be the fact that parents might reflect their own anxiety to the child and make them feel more anxious; and thus, have more pain. Parents having less anxiety, a higher level of knowledge and whose child was provided comfort were satisfied with the healthcare given about postoperative pain management (7). In this study, it was seen that parents in both intervention groups were more satisfied with the healthcare given to their children compared to the parents in the control group. These results were also found to be consistent with literature data.

No significant difference was found between the parents in both study groups based on satisfaction. Parents see the experience of pain during postoperative period as an expected situation (30). Therefore, it can be stated that they were satisfied with the interventions made for their children (finger puppet plays played by themselves as well as nurses) and the interest shown to them.

\section{CONCLUSION}

Finger puppet plays effectively decreased postoperative pain in children. Finger puppet plays can be used to decrease postoperative pain by the nurses as an independent role. This study highlights that puppet plays can be used by the nurses and parents for pain relief in children as a non-pharmacological method. Also, inclusion of parents in the plays has a positive effect on postoperative pain in children and on parental satisfaction. Pediatric nursing care for pain management should include distraction techniques and inclusion of parents. However, nurses may not be willing to use these distraction techniques and their attitudes towards parent inclusion in postoperative pain relief in children can be negative. Further nursing education programs addressing non-pharmacological techniques such as distraction techniques and parent inclusion for pain relief can be beneficial for children.

Acknowledgment: No external or intramural funding was received. This study is presented in IV. Congress of International Child Development (Ankara/ Turkey, Octb 22nd - 24th 2018)

Declaration of interest: The authors report no actual or potential conflicts of interest.

\section{REFERENCES}

[1] Kozlowski LJ, Kost-Byerly S, Colantuoni E, Thompson CB, Vasquenza KJ, Rothman SK. Pain prevalence, intensity, assessment and management in a hospitalized pediatric population. Pain Manag Nurs. 2014;15(1):22-35.

[2] Twycross A, Collis S. How well is acute pain in children managed? A snapshot in one English hospital. Pain Manag Nurs. 2013;14(4):e204-15.

[3] Sng QW, He HG, Wang W, Taylor B, Chow A, Klainin-Yobas P. A meta-synthesis of children's experiences of postoperative pain management. Worldviews Evidence-Based Nurs. 2017;14(1):46-54.

[4] Smeland AH, Rustøen T, Næss T, Nybro L, Lundeberg S, Reinertsen $\mathrm{H}$. Children's views on postsurgical pain in recovery units in Norway: A qualitative study. J Clin Nurs. 2019;28(1112):2157-70.

[5] Fortier MA, Martin SR, Kain DI, Tan ET. Parental attitudes regarding analgesic use for children: Differences in ethnicity and language. J Pediatr Surg. 2011;46(11):2140-5.

[6] Dongara AR, Shah SN, Nimbalkar SM, Phatak AG, Nimbalkar AS. Knowledge of and Attitudes Regarding Postoperative Pain among the Pediatric Cardiac Nursing Staff: An Indian Experience. Pain Manag Nurs. 2015;16(3):314-20. Available from: http://dx.doi.org/10.1016/j.pmn.2014.08.009

[7] Fincher W, Shaw J, Ramelet A. The effectiveness of a standardised preoperative preparation in reducing child and parent anxiety : a single-blind randomised controlled trial. J Clin Exp Investig. 2012;21:946-55.

[8] Ullan AM, Belver MH, Fernandez E, Lorente F, Badıa M, Fernandez B. The effect of a program to promote play to reduce children's post-surgical pain: With plush toys, it hurts less. Pain Manag Nurs. 2014;15(1):273-82.

[9] Yun OB, Kim SJ, Jung D. Effects of a clown-nurse educational Intervention on the reduction of postoperative anxiety and pain among preschool children and their accompanying parents in South Korea. J Pediatr Nurs. 2015;30:e89-99.

[10] Topan A, Şahin ÖÖ. Evaluation of efficiency of puppet show in decreasing fears of school-age children against medical procedures in Zonguldak (Turkey). J Pak Med Assoc. 2019;69(6):817-22. 
[11] Azadimanesh P, Hosseinkhanzadeh A, Hakim-javadi M, Vatankhah M. Effect of puppet play therapy on aggression of children with ADHD. J Urmia Univ Med Sci. 2017;28(2):83-90.

[12] Sparapani V de C, Borges ALV, Pan IR de ODR, Nascimento LC. Children with type 1 diabetes mellitus and their friends : the influence of this interaction in the management of the disease 1. Rev Latino-Am Enferm. 2012;20(1):117-25.

[13] Sposito AMP, Montigny F de, Sparapani V de C, Lima RAG de, Silva-Rodrigues FM, Pfeifer LI. Puppets as a strategy for communication with Brazilian children with cancer. Nurs Heal Sci. 2016;18:30-7.

[14] McGrath PJ, Johnson G, Goodman JT, Schillinger J, Dunn J, Chapman J. CHEOPS: A behavioral scale for rating postoperative pain in children. Adv Pain Res Ther. 1985;9:395-402.

[15] Kurt A, Seval M, Afacan C. Children's Hospital of Eastern Ontario Pain Scale: The study of validity and reliability. J Educ Res Nurs. 2020;17(1):9-16.

[16] Ulus B, Kubilay G. Turkish adaptation of the Pedsql health care parent satisfaction scale. ACU Sağlık Bil Derg. 2012;1(3):44-50.

[17] Reid-Searl K, Quinney L, Dwyer T, Vieth L, Nancarrow L, Walker B. Puppets in an acute paediatric unit: Nurse's experiences. Collegian. 2016;24(5):441-7.

[18] He HG, Zhu L, Cheung H, Li W, Wang W, Vehvil K. A randomized controlled trial of the effectiveness of a therapeutic play intervention on outcomes of children undergoing inpatient elective surgery : A study protocol. J Adv Nurs. 2014;70(2):43142.

[19] Smeland AH, Twycross A, Lundeberg S, Rustøen T. Nurses' knowledge, attitudes and clinical practice in pediatric postoperative pain management. Pain Manag Nurs. 2018;19(6):585-98.

[20] Twycross A, Forgeron P, Williams A. Paediatric nurses' postoperative pain management practices in hospital based non-critical care settings : A narrative review. Int J Nurs Stud. 2015;52(4):836-63.
[21] Eid T, Manias E, Bucknall T, Almazrooa A. Nurses' knowledge and attitudes regarding pain in Saudi Arabia. Pain Manag Nurs. 2014;15(4):e25-36.

[22] [22] Lim SH, Mackey S, Liam JL, He HG. An exploration of Singaporean parental experiences in managing schoolaged children's postoperative pain: a descriptive qualitative approach. J Clin Nurs. 2012;21(5-6):860-9.

[23] Valizadeh F, Ahmadi F, Zarea K. Neglect of postoperative pain management in children: A qualitative study based on the experiences of parents. J Pediatr Nurs. 2016;31(4):439-48.

[24] Nascimento LC, Warnock F, Pan R, Silva-Rodrigues FM, Castral TC, De Bortoli PS. Parents' participation in managing their children's postoperative pain at home: An integrative literature review. Pain Manag Nurs. 2019;20(5):444-454.

[25] Longard J, Twycross A, Williams AM, Hong P, Chorney J. Parents' experiences of managing their child's postoperative pain at home: an exploratory qualitative study. J Clin Nurs. 2016;25(17-18):2619-28.

[26] Walther-Larsen S, Aagaard GB, Friis SM, Petersen T, MøllerSonnergaard J, Rømsing J. Structured intervention for management of pain following day surgery in children. Paediatr Anaesth. 2016;26(2):151-7.

[27] Chorney JM, Twycross A, Mifflin K, Archibald K. Can we improve parents' management of their children's postoperative pain at home ? Pain Res Manag. 2014;19(4):115-23.

[28] Dorkham MC, Chalkiadis GA, Sternberg BSVU, Davidson AJ. Effective postoperative pain management in children after ambulatory surgery, with a focus on tonsillectomy : barriers and possible solutions. Pediatr Anesth. 2014;24:239-48.

[29] Scalford D, Flynn-roth R, Howard D, Phillips E, Ryan E, Davis KF. Pain Management of Children Aged 5 to 10 Years After Adenotonsillectomy. J PeriAnesthesia Nurs. 2013;28(6):35360.

[30] Twycross A, Finley GA. Children's and parents' perceptions of postoperative pain management: a mixed methods study. J Clin Nurs. 2013;22:3095-108. 